\title{
Análise da influência de alguns fatores socioeconômicos e demográficos no consumo domiciliar de carnes no Brasil
}

\author{
Madalena Maria Schlindwein* \\ Ana Lúcia Kassouf**
}

Resumo: Dadas as significativas mudanças no padrão de consumo alimentar das famílias brasileiras, em paralelo a importantes alterações em fatores como a urbanização e a participação da mulher no mercado de trabalho, este artigo tem como objetivo analisar a influência de alguns fatores socioeconômicos e demográficos no padrão de consumo de carnes da população brasileira. Os dados utilizados são oriundos da Pesquisa de Orçamentos Familiares (POF) 2002-2003, realizada pelo Instituto Brasileiro de Geografia e Estatística (IBGE). Utilizaram-se os microdados da POF e o procedimento em dois estágios de Heckman para analisar a influência dos fatores socioeconômicos no consumo domiciliar de carne bovina, suína e de frango. Os resultados mostram que os fatores socioeconômicos e demográficos possuem uma influência significativa nos padrões de consumo domiciliar de carnes no Brasil.

Palavras-chave: consumo de carne, fatores socioeconômicos, procedimento de Heckman.

Classificação JEL: C13

*Doutora em Economia Aplicada, pela ESALQ-USP. madalena_wein@hotmail.com

**Professora Titular do Departamento de Economia da ESALQ-USP.

alkassou@esalq.usp.br 
Abstract: Due to the changes in food consumption pattern by Brazilian families, together with an increase in urbanization and women labor participation, this article aims to study the influence of some socio-economic factors on the meat consumption pattern in Brazil. The data set used is a Household Budget Survey - "Pesquisa de Orçamentos Familiares" (POF) 2002-2003", carried out by the Brazilian Institute of Geography and Statistics (IBGE). Heckman two stages procedure was applied to the data to analyse the influence of socio-economic factors on the household consumption of beef, pork and poultry. The results show that the socio-economic and demographic factors have a large influence on the household meat consumption pattern in Brazil.

Key words: meat consumption, socio-economic factors, Heckman procedure.

\section{JEL Classification: C13}

\section{Introdução}

Ao longo das últimas décadas vêm ocorrendo muitas mudanças socioeconômicas e demográficas em todas as regiões do mundo. Especificamente para o Brasil, tem-se observado importantes mudanças na composição das famílias, na participação da mulher no mercado de trabalho e na urbanização, entre outros.

Essas mudanças se dão em paralelo com uma nova tendência de gastos familiares com alimentação. Segundo Ruel, Haddad e Garrett (1999), existem sérias implicações resultantes de mudanças nos padrões dietéticos e de atividades associadas com a urbanização. Destaque-se que, atualmente, $83 \%$ da população brasileira vive em áreas urbanas, enquanto em 1970 esse percentual era de apenas 56\% (IBGE, 2004a).

Para destacar as mudanças no padrão de consumo alimentar das famílias brasileiras, a Tabela 1 apresenta um comparativo entre as quantidades adquiridas dos produtos: feijão, arroz, carne bovina, carne de frango, iogurte, refrigerante e alimentos preparados $^{1}$, no período de

${ }^{1}$ Com o intuito de se fazer uma comparação dos resultados da Pesquisa de Orçamentos Familiares (POF) 2002-2003 com as outras POFs e o Estudo Nacional da Despesa Familiar (ENDEF) 1974-1975, trabalhou-se com as Regiões Metropolitanas, considerando as quantidades adquiridas de produtos alimentares apenas por meio de despesas mone 
1974 a 2003. Verifica-se uma considerável redução no consumo domiciliar de alimentos que demandam um maior tempo para o preparo, como o arroz, o feijão e as carnes e um significativo aumento no consumo de alimentos preparados, iogurtes e refrigerantes, que são produtos práticos e que não exigem muito tempo para o seu preparo.

Tabela 1 - Quantidade anual per capita de alimentos adquiridos para consumo no domicílio - Brasil - 1974-2003

\begin{tabular}{l|r|r|r|r}
\hline \multirow{2}{*}{ Produtos selecionados } & \multicolumn{4}{|c}{$\begin{array}{l}\text { Quantidade anual per capita de alimentos adquiridos } \\
\text { para consumo no domicílio (em kg) (1) }\end{array}$} \\
\cline { 2 - 5 } & $\begin{array}{r}\text { ENDEF } \\
1974-1975\end{array}$ & $\begin{array}{c}\text { POF } \\
1987-1988\end{array}$ & $\begin{array}{c}\text { POF } \\
1995-1996\end{array}$ & $\begin{array}{c}\text { POF } \\
2002-2003\end{array}$ \\
\hline Arroz polido & 31,571 & 29,725 & 26,483 & 17,110 \\
Feijão & 14,698 & 12,134 & 10,189 & 9,220 \\
Carne bovina & 16,161 & 18,509 & 20,800 & 14,574 \\
Frango & 24,249 & 22,837 & 22,679 & 14,190 \\
Iogurte & 0,363 & 1,140 & 0,732 & 2,910 \\
Refrigerante de guaraná (2) & 1,297 & 2,674 & 4,280 & 7,656 \\
Alimentos preparados & 1,706 & 1,376 & 2,718 & 5,398 \\
\hline
\end{tabular}

Fonte: Elaborada a partir de IBGE (2004b, p.103)

(1) Regiões Metropolitanas de Belém, Fortaleza, Recife, Salvador, Belo Horizonte, Rio de Janeiro, São Paulo, Curitiba, Porto Alegre e Brasília-DF.

(2) As quantidades foram transformadas em kg, considerando-se volume igual a peso (1litro = 1kg).

De acordo com os dados da Tabela 1, verifica-se que houve uma mudança considerável e gradual no consumo de arroz, feijão, carne bovina, frango, iogurte, refrigerante e alimentos preparados no Brasil. Observa-se que entre o período de 1974 a 2003 houve uma redução de $46 \%$ na aquisição domiciliar de arroz polido, $37 \%$ na aquisição de feijão, $10 \%$ de carne bovina e $41 \%$ de frango. Por outro lado, houve um aumento significativo na aquisição de alimentos preparados $216 \%$, iogurtes $702 \%$ e refrigerantes $490 \%$. É importante destacar que esses dados se referem aos alimentos adquiridos para consumo no domicílio.

tárias, uma vez que nas outras POFs não se investigou as aquisições não-monetárias. Desta forma, é possível que haja alguma diferença entre estas quantidades e as apresentadas ao longo deste estudo. 
Acredita-se que essa mudança no padrão de consumo alimentar de forma geral e, especificamente, dos alimentos que constam na Tabela 1, se deve em grande parte às mudanças socioeconômicas e demográficas que vêm ocorrendo no Brasil, como, por exemplo, a intensificação do processo de urbanização e o aumento da participação da mulher no mercado de trabalho. Atualmente, $83 \%$ da população brasileira vivem no meio urbano e $54 \%$ das mulheres brasileiras, que são ou chefes de família ou cônjuges, trabalham fora de casa (SCHLINDWEIN, 2006). O fator preço também não deve ser desconsiderado, pois certamente possui uma forte influência sobre o padrão de consumo alimentar das famílias brasileiras.

Esses dados são um bom indicativo da mudança nos padrões de consumo alimentar nos domicílios brasileiros, mudança essa que pode afetar significativamente o padrão nutricional e, conseqüentemente, a saúde e a qualidade de vida das pessoas. Entender melhor qual o nível de influência dos fatores socioeconômicos e demográficos associados a essa mudança no consumo alimentar é muito importante para a formulação de políticas públicas relacionadas à alimentação, saúde, qualidade de vida e, em suma, ao desenvolvimento econômico do país.

Muitos estudos vêm sendo feitos na tentativa de avaliar os efeitos de fatores socioeconômicos e demográficos nos padrões de consumo de alimentos para diversas regiões do mundo e vários autores já identificaram a importância de variáveis como a renda, raça, local de residência, tamanho e composição da família em mudanças nos padrões de consumo (PROCHASKA; SCHRIMPER, 1973; SENAUER, 1979; REDMAN, 1980; SENAUER; SAHN; ALDERMAN, 1986; McCRAKEN; BRANDT, 1987; PARK; CAPPS, 1997; SDRALI, 2005; SICHIERI; CASTRO; MOURA, 2005). Como exemplos de estudos nessa linha realizados para o Brasil, citam-se os trabalhos de Hoffmann (1995), que analisou o efeito da urbanização sobre o consumo de feijão e de Bertasso (2000), que fez uma análise sobre os efeitos de algumas variáveis socioeconômicas sobre o padrão de consumo de alimentos.

\section{Metodologia}

A influência dos fatores socioeconômicos e demográficos nos padrões de consumo de alimentos, de acordo com McCracken e Brand 
(1987), é mais apropriadamente analisada através do contexto teórico da economia da produção domiciliar. Para Deaton e Muellbauer (1986), a forma mais geral pela qual é possível incorporar suposições especiais em modelos de comportamento das famílias é através dessa teoria. Este novo contexto teórico da produção domiciliar, formulado por Becker (1965), Lancaster (1966) e outros, enfatiza o fato de que os bens de mercado e serviços não levam à utilidade, mas são insumos no processo que gera produtos que produzem utilidade.

A teoria da produção domiciliar integra a teoria da firma (produção) e do consumidor. A família deriva utilidade de um bem, ou cesta de bens $Z$, que não podem ser comprados no mercado, sendo produzido no domicílio, a partir de insumos comprados no mercado, mais o tempo utilizado para produzir esses bens (DEATON; MUELLBAUER, 1986).

$O$ método econométrico a ser utilizado para a análise empírica é o procedimento em dois estágios de Heckman. O procedimento de Heckman aparece na literatura como uma alternativa aos métodos de máxima verossimilhança para estimar os parâmetros em modelos de seleção amostral (HOFFMANN e KASSOUF, 2005). Como em muitos domicílios não há aquisição de carnes, ou porque realmente não consomem o produto ou porque não o adquiriram na semana da pesquisa realizada, a não correção da seletividade amostral ao se utilizar somente famílias com consumo positivo, pode levar a inconsistência na estimativa dos parâmetros.

No primeiro estágio do procedimento de Heckman, estima-se um modelo Probit cuja variável dependente é 1 se a família consome determinado tipo de carne e zero caso contrário.

$C_{i j}=\mathrm{f}_{i}$ (urbanização, região, características da mulher e do domicílio) $i=1, \ldots, n$ (1)

onde:

$C_{i j}=1$ se o dispêndio do domicílio $j$, com o bem $i$, for observado e zero caso contrário.

Os fatores demográficos incluem a região e urbanização. As características do domicílio são: renda domiciliar, expressa em logaritmo; composição familiar, que se refere ao total de pessoas por faixa etária 
no domicílio e sexo do chefe da família, sendo igual a 1 quando o homem é o chefe. As características da mulher chefe da família ou cônjuge incluem a idade, nível educacional e a raça. As variáveis sexo do chefe da família, raça, região e urbanização são binárias e mutuamente exclusivas. As variáveis renda, idade e anos de escolaridade da mulher chefe de família ou cônjuge e composição familiar são contínuas.

Uma regressão probit é estimada para cada um dos produtos: carne bovina, carne suína e frango.

O segundo estágio do procedimento de Heckman envolve a estimação de equações de dispêndio e pode ser expresso como:

$\ln G_{i j}=G_{i}\left(\ln Y_{j} ; E S_{j} ; U R_{j}, C F_{j}, I \hat{M} R_{i}\right), \quad i=1, \ldots, n$

sendo:

$\ln G_{i j}=\log$ do dispêndio com o produto $i$ no domicílio $j$;

$\ln Y_{j}=\log$ da renda do domicílio $j$;

$E S_{j}=$ anos de escolaridade da mulher chefe da família ou cônjuge;

$U R_{j}=$ localização do domicílio $j$, urbano - rural;

$C F_{j}=$ composição familiar do domicílio $j$, se refere ao número de pessoas, por faixa etária, no domicílio;

$I \hat{M} R_{i}=$ razão inversa de Mills, gerada pelas regressões probit, para os produtos $i$, no primeiro estágio.

O dispêndio com os produtos é expresso em logaritmo. As variáveis que representam as características do domicílio (renda domiciliar, composição familiar) e a urbanização são as mesmas definidas anteriormente. As variáveis sexo do chefe da família, idade e raça da mulher chefe de família ou cônjuge e região serão omitidas do segundo estágio. Por hipótese, uma vez que as decisões de consumo já foram tomadas, essas variáveis provavelmente não afetarão a magnitude do dispêndio. A razão inversa de Mills é uma variável gerada pelo próprio modelo com o intuito de corrigir o viés de seleção amostral. As regressões que correspondem ao segundo estágio serão estimadas utilizando apenas observações correspondentes a um respectivo gasto positivo. As estimativas das equações de dispêndio com as carnes (bovina, suína e frango) serão realizadas através da utilização do modelo de Mínimos Quadrados. Para maiores detalhes sobre o procedimento de Heckman, ver Hoffmann e Kassouf (2005); Greene (2003) ou Heckman (1979). 


\subsection{Dados}

Os dados utilizados neste trabalho são oriundos da Pesquisa de Orçamentos Familiares (POF) 2002-2003, realizada pelo Instituto Brasileiro de Geografia e Estatística (IBGE). Esta pesquisa visa mensurar, fundamentalmente, as estruturas de consumo, dos gastos e dos rendimentos das famílias e possibilita traçar um perfil das condições de vida da população brasileira a partir da análise de seus orçamentos domésticos. A coleta dos dados da referida pesquisa foi realizada nas áreas urbanas e rurais, em todo o território nacional, no período de julho de 2002 a junho de 2003, sendo entrevistados um total de 48.470 domicílios.

\section{Resultados e discussões}

\subsection{Análise preliminar dos dados}

É indiscutível a grande diferença nos hábitos alimentares da população brasileira, tanto entre as diversas regiões do país, quanto entre o meio rural e urbano, o que é compreensível dado que se trata de um país continental com grandes diferenças étnicas e culturais. O consumo per capita anual de carne bovina e de frango nos meios urbano e rural gira em torno de $17 \mathrm{~kg}$ e $13 \mathrm{~kg}$, respectivamente, mostrando pequena diferença. Já o consumo de carne suína é bem mais elevado no meio rural, enquanto o consumo per capita médio para o Brasil está em torno de $4 \mathrm{~kg}$, no meio rural esse consumo passa para mais de $7 \mathrm{~kg}$, como pode ser observado na Tabela 2. Destaque-se que esse consumo elevado da carne suína nas áreas rurais pode estar relacionado à produção própria, o que ainda é um hábito bastante comum, principalmente, nas pequenas propriedades rurais.

Comparando-se o consumo dos três tipos de carnes, observa-se que, enquanto o consumo de carne de frango é quase três vezes superior ao consumo de carne suína, o consumo de carne bovina é praticamente quatro vezes o consumo de carne suína. Quadro esse que se repete nas Grandes Regiões do país, se intensificando no Norte e Nordeste, como mostra a Tabela 2 .

Considerando as Grandes Regiões do país, é possível observar na 
Tabela 2 que o consumo domiciliar per capita de carne bovina da região Norte é $38 \%$ superior à média nacional e $63 \%$ superior ao consumo médio da região Sudeste, que é a região com o menor consumo per capita domiciliar. Analisando o consumo da carne suína, verifica-se que o consumo da região Sul é $90 \%$ maior que a média do Brasil e $273 \%$ superior ao consumo do Nordeste que é a região que menos consome esse tipo de carne. Já com relação ao consumo de frango, essa diferença no consumo entre as Grandes Regiões do país é a menos significativa, ou seja, o consumo domiciliar per capita médio da região Norte, que é a maior consumidora nacional é $38 \%$ superior ao consumo do Centro-Oeste, que é a menor consumidora. É importante destacar que os dados da Tabela 2 diferem dos da Tabela 1, uma vez que agora se está considerando o consumo do país como um todo e as quantidades adquiridas por meio tanto de despesas monetárias quanto não-monetárias, diferentemente dos dados da Tabela 1, onde se considerou apenas as Regiões Metropolitanas e as quantidades adquiridas por meio de despesas monetárias.

Tabela 2 - Aquisição alimentar domiciliar per capita anual de carnes - Brasil e Grandes Regiões, período 2002-2003

\begin{tabular}{l|r|r|r|r|r|r|r|r}
\hline & \multicolumn{6}{c}{ Aquisição alimentar domiciliar per capita anual (em kg) } \\
\cline { 2 - 9 } Produtos & \multicolumn{6}{c}{ Brasil } & \multicolumn{6}{c}{ Grandes Regiões } \\
\cline { 2 - 9 } & Total & Urbano & Rural & Norte & Nordeste & Sudeste & Sul & $\begin{array}{c}\text { Centro- } \\
\text { Oeste }\end{array}$ \\
\hline & & & & & & & & \\
Carne bovina & 17,694 & 17,761 & 17,364 & 24,361 & 17,817 & 14,946 & 21,781 & 17,935 \\
Carne suína & 4,654 & 4,103 & 7,332 & 3,069 & 2,378 & 5,087 & 8,865 & 3,995 \\
Frango & 13,562 & 13,664 & 13,064 & 16,586 & 12,411 & 13,209 & 15,893 & 12,039 \\
\hline
\end{tabular}

Fonte: IBGE (2004a)

A Figura 1 permite uma melhor visualização das diferenças no consumo das carnes bovina, suína e de frango entre as diversas regiões do Brasil. Verifica-se que a carne bovina é a carne mais consumida no país, em segundo lugar aparece o frango com um consumo apenas um pouco inferior ao da carne bovina. A carne suína aparece em terceiro lugar com um consumo bastante inferior ao das outras carnes. 
Figura 1 - Aquisição domiciliar per capita anual de carnes - Brasil e Grandes Regiões, período 2002-2003

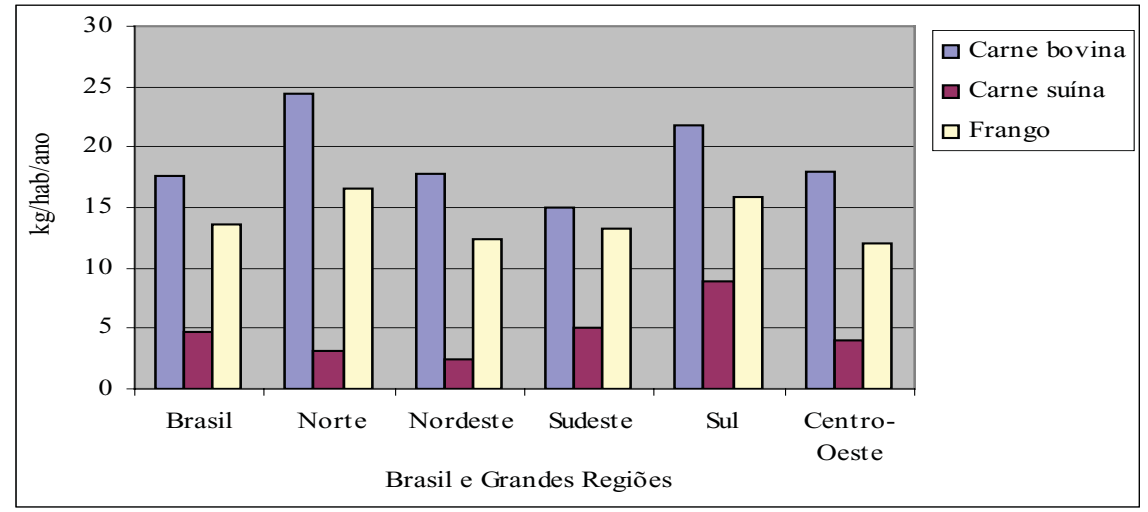

Fonte: Schlindwein (2006, p. 81)

Esse quadro se repete para todas as regiões, com a diferença de consumo entre as carnes variando um pouco mais em algumas regiões e um pouco menos em outras. A região Norte é a maior consumidora de carne bovina e de frango entre todas as regiões, já o consumo de carne suína é maior na região Sul. O Nordeste é a região brasileira com o menor consumo de carne suína, o Centro-Oeste é a região de menor consumo de frango e o Sudeste é a região de menor consumo de carne bovina.

Chamou a atenção o fato de a região Norte ser a maior consumidora per capita de carne bovina e de frango. Isto se deve, em parte, ao baixo preço dessas carnes no Norte do Brasil. O consumo de carne suína é bem mais elevada na região Sul, onde também se observa uma maior aquisição de embutidos (lingüiça, presunto, salsicha, etc.) e se somarmos o consumo dos três tipos de carne (bovina, suína e de frango) a região maior consumidora per capita de carnes do Brasil é a região Sul, com $46 \mathrm{~kg}$, enquanto que essa soma para a região Norte não passa de $44 \mathrm{~kg}$.

O mesmo quadro que se verificou para o consumo, também se observa para o dispêndio. Isto é, não há uma diferença muito significativa entre o gasto domiciliar urbano e rural para o caso da carne bovina e de frango. O gasto mensal com a carne bovina é de $\mathrm{R} \$ 26,97$ em média para o Brasil, valor que passa para $\mathrm{R} \$ 27,08$ na área urbana e para $\mathrm{R} \$$ 26,33 na rural. No caso do frango, o gasto médio mensal familiar no 
Brasil é de $R \$ 12,84$, sendo $R \$ 12,70$ no meio urbano e $R \$ 13,65$ no rural. Já com relação à carne suína, há uma grande diferença entre o dispêndio nos domicílios urbanos e rurais. Com um gasto médio mensal familiar de $\mathrm{R} \$ 5,32$ para o Brasil, $\mathrm{R} \$ 4,85$ para o meio urbano e $\mathrm{R} \$$ 7,92 para o rural. O dispêndio rural com carne suína é $63 \%$ superior ao urbano, como pode ser verificado na Tabela 3.

Tabela 3 - Gasto domiciliar médio mensal com alimentação Brasil e Grandes Regiões, período 2002-2003

\begin{tabular}{l|r|r|r|r|r|r|r|r}
\hline \multirow{2}{*}{ Produtos } & \multicolumn{6}{c}{ Gasto domiciliar médio com alimentação (em R\$) } \\
\cline { 2 - 9 } & Total & Urbano & Rural & Norte & Nordeste & Sudeste & Sul & $\begin{array}{c}\text { Centro- } \\
\text { Oeste }\end{array}$ \\
\cline { 2 - 9 } & \multicolumn{10}{|c}{ Brasil } & & & & & & \\
Carne bovina & 26,97 & 27,08 & 26,33 & 37,02 & 29,77 & 23,84 & 27,79 & 25,85 \\
Carne suína & 5,32 & 4,85 & 7,92 & 3,63 & 2,96 & 6,16 & 7,89 & 4,10 \\
Frango & 12,84 & 12,70 & 13,65 & 18,32 & 14,30 & 11,90 & 12,24 & 10,07 \\
Carnes (1) & 45,14 & 44,64 & 47,91 & 58,97 & 47,04 & 41,9 & 47,93 & 40,03 \\
\hline
\end{tabular}

Fonte: IBGE (2004a)

(1) Carne bovina, suína e frango.

Entre as Grandes Regiões, o Norte se destaca com o maior gasto médio mensal familiar com carne bovina ( $\mathrm{R} \$ 37,02)$ e com frango ( $\mathrm{R} \$$ 18,32 ), valores $37 \%$ e $43 \%$ acima da média nacional, respectivamente. Com relação à carne suína, é o Sul do país que apresenta o maior gasto médio (R\$ 7,89), valor $48 \%$ acima da média nacional, enquanto a região Nordeste apresenta o menor gasto $(\mathrm{R} \$ 2,96), 44 \%$ inferior à média brasileira. A região Sudeste se destaca pelo menor dispêndio com carne bovina, $12 \%$ abaixo da média nacional e a região Centro-Oeste pelo menor gasto médio mensal familiar com frango, $22 \%$ inferior à média.

\subsection{Variáveis utilizadas}

A descrição, freqüência, média ponderada e desvio-padrão de cada variável utilizada nas regressões está apresentada na Tabela 4. A freqüência média de consumo das carnes (bovina, suína e de aves) em conjunto é de $65 \%$. Entre os diferentes tipos de carne, a bovina aparece 
com a maior freqüência média de aquisição, tendo sido adquirida em $49 \%$ dos domicílios brasileiros. Em segundo lugar aparece o frango com $37 \%$ e em terceiro a carne suína com $18 \%$.

Algumas variáveis descrevem as características da mulher chefe de família ou cônjuge. Assim, pode-se dizer que a mulher brasileira, que é ou chefe de família ou cônjuge, tem a idade média de 42,8 anos e que $54 \%$ dessas mulheres trabalham. As mulheres chefes de família ou cônjuges possuem em torno de 6,02 anos de estudo, sendo que $11 \%$ delas não possuem instrução, 59\% cursaram o ensino fundamental, $21 \%$ o ensino médio e apenas $9 \%$ o ensino superior. Quanto à raça, em média $55 \%$ dessas mulheres são brancas, $37 \%$ pardas, $7 \%$ negras, $0,6 \%$ são da raça amarela e $0,3 \%$ são indígenas (Tabela 4).

Em torno de $16 \%$ dos domicílios possuem uma renda média mensal de até RS 400,00, 14\% auferem uma renda média entre R\$400,00 e R \$ $600,00,21 \%$ entre $\mathrm{R} \$ 600,00$ e $\mathrm{R} \$ 1.000,00,18 \%$ entre $\mathrm{R} \$ 1.000,00$ e $\mathrm{R} \$$ $1.600,00,16 \%$ entre $\mathrm{R} \$ 1.600,00$ e $\mathrm{R} \$ 3.000,00$ e $15 \%$ dos domicílios brasileiros têm uma renda mensal média de mais de $\mathrm{R} \$ 3.000,00$. No que se refere à localização dos domicílios, em média, $6 \%$ se localizam na região Norte, $7 \%$ na região Centro-Oeste, $16 \%$ na região Sul, $25 \%$ na região Nordeste e $46 \%$ dos domicílios brasileiros se localizam na região Sudeste. Em média, em $74 \%$ das famílias, é o homem quem é considerado o chefe da família, destaque-se que já é bastante notável o percentual de famílias onde a mulher é considerada chefe, $26 \%$.

Em torno de $85 \%$ dos domicílios brasileiros se localizam na área urbana e apenas $15 \%$ no meio rural. Quanto à composição familiar tem-se, no Brasil, em média, 0,5 criança menor de 6 anos por domicílio, 0,43 criança com idade entre 7 e 12 anos e 0,45 adolescente entre 13 e 18 anos. O número de jovens entre 19 e 25 anos é de 0,5 pessoas por domicílio, de adultos entre 26 e 40 é de 0,8 e de adultos entre 41 e 60 anos 0,7 indivíduos por domicílio. Já a média de idosos acima de 60 anos é de 0,3 por domicílio. 

carnes no Brasil

Tabela 4 - Descrição das variáveis, freqüências, médias e desvios-padrões

\begin{tabular}{|c|c|c|c|c|}
\hline \multirow{2}{*}{ Variáveis } & \multirow[t]{2}{*}{ Descrição das variáveis } & \multicolumn{3}{|c|}{ Brasil } \\
\hline & & Freq. & média & d.p. \\
\hline \multicolumn{5}{|l|}{ Var. Dependentes } \\
\hline \multicolumn{5}{|l|}{ Consumo (1) } \\
\hline Carnes & $=1$ se consome & 65,04 & 35,91 & 56,76 \\
\hline Carne Bovina & $=1$ se consome & 49,10 & 17,69 & 35,49 \\
\hline Carne suína & $=1$ se consome & 17,90 & 4,65 & 27,79 \\
\hline Frango & $=1$ se consome & 36,56 & 13,56 & 25,87 \\
\hline \multicolumn{5}{|l|}{ Var. Exógenas } \\
\hline Ln renda & Logaritmo da renda domiciliar & - & 6,94 & 1,01 \\
\hline Tamanho da família & Número de pessoas no domicílio & - & 3,63 & 1,83 \\
\hline Anos de estudo & $\begin{array}{l}\text { Anos de estudo da mulher chefe } \\
\text { ou cônjuge }\end{array}$ & - & 6,02 & 4,49 \\
\hline Idade & Idade da mulher chefe ou cônjuge & - & 42,8 & 15,25 \\
\hline Trabalho & $\begin{array}{l}=1 \text { se a mulher chefe ou cônjuge } \\
\text { trabalha }\end{array}$ & 53,68 & 0,54 & 0,50 \\
\hline Instrução1 (2) & $=1$ sem instrução & 10,85 & 0,11 & 0,31 \\
\hline Instrução2 (2) & $=1$ ensino fundamental & 59,32 & 0,59 & 0,49 \\
\hline Instrução3 (2) & $=1$ ensino médio & 20,76 & 0,21 & 0,41 \\
\hline Instrução4 (2) & $=1$ ensino superior & 9,07 & 0,09 & 0,29 \\
\hline Branca & $\begin{array}{l}=1 \text { se a raça da mulher chefe } \\
\text { ou cônjuge é branca }\end{array}$ & 54,61 & 0,55 & 0,50 \\
\hline Parda & $\begin{array}{l}=1 \text { se a raça da mulher chefe } \\
\text { ou cônjuge é parda }\end{array}$ & 37,12 & 0,37 & 0,48 \\
\hline Preta & $\begin{array}{l}=1 \text { se a raça da mulher chefe } \\
\text { ou cônjuge é preta }\end{array}$ & 7,30 & 0,07 & 0,26 \\
\hline Amarela & $\begin{array}{l}=1 \text { se a raça da mulher chefe } \\
\text { ou cônjuge é amarela }\end{array}$ & 0,62 & 0,006 & 0,08 \\
\hline Indígena & $\begin{array}{l}=1 \text { se a raça da mulher chefe } \\
\text { ou cônjuge é indígena }\end{array}$ & 0,34 & 0,003 & 0,06 \\
\hline Sexo do chefe & $\begin{array}{l}=1 \text { se o homem é o chefe da } \\
\text { família }\end{array}$ & 73,66 & 0,74 & 0,44 \\
\hline Setor & $\begin{array}{l}=1 \text { se a residência estiver } \\
\text { localizada na área urbana }\end{array}$ & 84,72 & 0,85 & 0,36 \\
\hline Região Norte & $\begin{array}{l}=1 \text { se o domicílio está na região } \\
\text { Norte }\end{array}$ & - & 0,06 & 0,25 \\
\hline Região Nordeste & $\begin{array}{l}=1 \text { se o domicílio está na região } \\
\text { Nordeste }\end{array}$ & - & 0,25 & 0,43 \\
\hline Região Sudeste & $\begin{array}{l}=1 \text { se o domicílio está na região } \\
\text { Sudeste }\end{array}$ & - & 0,46 & 0,50 \\
\hline
\end{tabular}




\begin{tabular}{|c|c|c|c|c|}
\hline Região Sul & $\begin{array}{l}=1 \text { se o domicílio está na região } \\
\text { Sul }\end{array}$ & - & 0,16 & 0,36 \\
\hline $\begin{array}{l}\text { Região Centro- } \\
\text { Oeste }\end{array}$ & $\begin{array}{l}=1 \text { se o domicílio está na região } \\
\text { Centro-Oeste }\end{array}$ & - & 0,07 & 0,26 \\
\hline Idade1 & $\begin{array}{l}\text { Número de crianças } \leq 6 \text { anos no } \\
\text { domicílio }\end{array}$ & - & 0,46 & 0,77 \\
\hline Idade2 & Número de crianças $\geq 7 \leq 12$ anos & - & 0,43 & 0,73 \\
\hline Idade3 & $\begin{array}{l}\text { Número de adolescentes } \geq 13 \leq \\
18 \text { anos }\end{array}$ & - & 0,45 & 0,76 \\
\hline Idade4 & Número de jovens $\geq 19 \leq 25$ anos & - & 0,48 & 0,76 \\
\hline Idade5 & Número de adultos $\geq 26 \leq 40$ anos & - & 0,83 & 0,84 \\
\hline Idade6 & Número de adultos $\geq 41 \leq 60$ anos & - & 0,67 & 0,79 \\
\hline Idade7 & Número de idosos $\geq 61$ anos & - & 0,30 & 0,59 \\
\hline Rendimento1 & $\begin{array}{l}=1 \text { se a renda domiciliar for } \leq R \$ \\
400,00\end{array}$ & 16,24 & 0,16 & 0,37 \\
\hline Rendimento2 & $\begin{array}{l}=1 \text { se a renda for }>400,00 \text { e } \leq \\
600,00\end{array}$ & 13,90 & 0,14 & 0,35 \\
\hline Rendimento3 & $\begin{array}{l}=1 \text { se a renda for }>600,00 \mathrm{e} \leq \\
1.000,00\end{array}$ & 20,95 & 0,21 & 0,41 \\
\hline Rendimento4 & $\begin{array}{l}=1 \text { se a renda for }>1.000,00 \mathrm{e} \leq \\
1.600,00\end{array}$ & 17,80 & 0,18 & 0,38 \\
\hline Rendimento5 & $\begin{array}{l}=1 \text { se a renda for }>1.600,00 \text { e } \leq \\
3.000,00\end{array}$ & 16,39 & 0,16 & 0,37 \\
\hline Rendimento6 & $\begin{array}{l}=1 \text { se a renda domiciliar for }> \\
3.000,00\end{array}$ & 14,72 & 0,15 & 0,35 \\
\hline
\end{tabular}

Fonte: Dados da pesquisa, obtidos a partir de IBGE (2004a)

(1) Os valores médios de consumo se referem ao consumo per capita médio domiciliar.

(2) Se refere ao nível de instrução da mulher chefe ou cônjuge.

\subsection{Resultados econométricos}

\subsubsection{Resultados das equações probit}

As regressões probit, cujos resultados estão apresentados na Tabela 5 , mostram os fatores que afetam a probabilidade de se consumir determinado tipo de carne. Em todas as regressões probit, o teste da razão de verossimilhança, que testa se todos os coeficientes exceto a constante são zero, foi altamente significativo. Os coeficientes da razão inversa de Mills (Lambda) foram estatisticamente significativos, indicando a necessidade de correção do viés de seleção amostral. O sinal negativo dessa variável para a carne bovina, suína e de frango indica que fato- 
res não mensurados que elevam a probabilidade de consumo reduzem o gasto com esses produtos. Esses fatos indicam que a não utilização do procedimento em dois estágios de Heckman poderia gerar um viés sobre os verdadeiros efeitos das variáveis exógenas sobre o gasto domiciliar com a aquisição dos produtos em análise.

Com base nos resultados (efeitos marginais e testes) das regressões probit para as carnes bovina, suína e de frango, apresentados na Tabela 5 , verifica-se que a renda exerce uma influência positiva e altamente significativa na probabilidade de consumo dos três tipos de carne. Ou seja, um aumento na renda domiciliar eleva a probabilidade de consumo familiar de carne bovina, suína e frango.

A composição familiar também apresentou resultados altamente significativos. O sinal positivo dessa variável significa que a probabilidade de consumo é diretamente proporcional ao número de indivíduos por faixa etária. Ou seja, um aumento no tamanho da família eleva a probabilidade de consumo de carne bovina, suína e de frango. No caso da carne bovina, essa variável só é significativa para as faixas etárias acima de 12 anos, como pode ser observado na Tabela 5 .

Tabela 5 - Resultados dos efeitos marginais do Modelo Probit para os produtos: carne bovina, carne suína e frango

\begin{tabular}{lcccc}
\hline \multirow{2}{*}{ Variáveis } & \multicolumn{3}{c}{ Equações Probit } \\
\cline { 2 - 4 } & Carne bovina & Carne suína & Frango \\
\hline \multirow{3}{*}{ Renda domiciliar (log) } & 0,0327 & 0,0248 & 0,0282 \\
& $(9,81)^{* * *}$ & $(10,66)^{* * *}$ & $(8,75)^{* * *}$ \\
Região Norte & 0,211 & $-0,0833$ & 0,07103 \\
Região Nordeste & $(24,20)^{* * *}$ & $(-15,34)^{* * *}$ & $(8,07)^{* * *}$ \\
Região Sul & 0,174 & $-0,0488$ & 0,0754 \\
& $(23,81)^{* * *}$ & $(-10,14)^{* * *}$ & $(10,56)^{* * *}$ \\
Região Centro-Oeste & 0,0712 & 0,0347 & 0,020042 \\
& $(7,95)^{* * *}$ & $(5,73)^{* * *}$ & $(2,28)^{* *}$ \\
Anos de escolaridade & 0,0568 & $-0,0686$ & $-0,0626$ \\
& $(6,83)^{* * *}$ & $(-13,32)^{* * *}$ & $(-7,75)^{* * *}$ \\
Raça preta & $-0,00065$ & $-0,000705$ & $-0,00328$ \\
& $(-0,89)$ & $(-1,38)$ & $(-4,62)^{* * *}$ \\
& $-0,0136$ & 0,0077 & 0,0139 \\
& $(-1,24)$ & $(0,99)$ & $(1,30)$
\end{tabular}




\begin{tabular}{|c|c|c|c|}
\hline Raça amarela & $\begin{array}{c}0,00706 \\
(0,18)\end{array}$ & $\begin{array}{c}-0,0362 \\
(-1,36)\end{array}$ & $\begin{array}{c}-0,0252 \\
(-0,65)\end{array}$ \\
\hline Raça parda & $\begin{array}{c}-0,0039 \\
(-0,70)\end{array}$ & $\begin{array}{c}0,00421 \\
(1,08)\end{array}$ & $\begin{array}{l}0,01023 \\
(1,91)^{*}\end{array}$ \\
\hline Raça indígena & $\begin{array}{c}-0,0924 \\
(-2,44)^{* *}\end{array}$ & $\begin{array}{c}-0,04503 \\
(-1,66)^{*}\end{array}$ & $\begin{array}{c}-0,0474 \\
(-1,29)\end{array}$ \\
\hline \multicolumn{4}{|c|}{ Composição familiar (número de pessoas por faixa etária) } \\
\hline Até 6 anos & $\begin{array}{c}0,00122 \\
(0,37)\end{array}$ & $\begin{array}{c}0,00383 \\
(1,67)^{*}\end{array}$ & $\begin{array}{l}0,00669 \\
(2,12)^{* *}\end{array}$ \\
\hline Entre 7 e 12 anos & $\begin{array}{c}0,00313 \\
(0,93)\end{array}$ & $\begin{array}{c}0,01012 \\
(4,39)^{* * *}\end{array}$ & $\begin{array}{c}0,0149 \\
(4,63)^{* * *}\end{array}$ \\
\hline Entre 13 e 18 anos & $\begin{array}{c}0,0164 \\
(5,12)^{* * *}\end{array}$ & $\begin{array}{c}0,0142 \\
(6,51)^{* * *}\end{array}$ & $\begin{array}{c}0,0314 \\
(10,25)^{* * *}\end{array}$ \\
\hline Entre 19 e 25 anos & $\begin{array}{c}0,0229 \\
(6,51)^{* * *}\end{array}$ & $\begin{array}{c}0,00856 \\
(3,57)^{* * *}\end{array}$ & $\begin{array}{c}0,0266 \\
(7,94)^{* * *}\end{array}$ \\
\hline Entre 26 e 40 anos & $\begin{array}{c}0,0433 \\
(10,84)^{* * *}\end{array}$ & $\begin{array}{c}0,0136 \\
(5,02)^{* * *}\end{array}$ & $\begin{array}{c}0,04081 \\
(10,71)^{* * *}\end{array}$ \\
\hline Entre 41 e 60 anos & $\begin{array}{c}0,04035 \\
(8,51)^{* * *}\end{array}$ & $\begin{array}{c}0,0157 \\
(4,81)^{* * *}\end{array}$ & $\begin{array}{c}0,04025 \\
(8,85)^{* * *}\end{array}$ \\
\hline Mais de 60 anos & $\begin{array}{c}0,0468 \\
(6,57)^{* * *}\end{array}$ & $\begin{array}{c}0,00569 \\
(1,16)\end{array}$ & $\begin{array}{c}0,0432 \\
(6,34)^{* * *}\end{array}$ \\
\hline Idade da mulher & $\begin{array}{c}0,0007068 \\
(2,27)^{* *}\end{array}$ & $\begin{array}{c}-0,000386 \\
(-1,75)^{*}\end{array}$ & $\begin{array}{c}-0,000168 \\
(-0,56)\end{array}$ \\
\hline Área urbana & $\begin{array}{c}0,0732 \\
(11,85)^{* * *}\end{array}$ & $\begin{array}{c}-0,0238 \\
(-5,40)^{* * *}\end{array}$ & $\begin{array}{c}0,0174 \\
(2,93)^{* * *}\end{array}$ \\
\hline $\begin{array}{l}\text { Sexo do chefe da } \\
\text { família }\end{array}$ & $\begin{array}{c}0,0472 \\
(7,27)^{* * *}\end{array}$ & $\begin{array}{c}0,00564 \\
(1,24)\end{array}$ & $\begin{array}{c}0,0193 \\
(3,07)^{* * *}\end{array}$ \\
\hline Lambda & $\begin{array}{c}-0,631 \\
(-13,11)^{* * *}\end{array}$ & $\begin{array}{c}-0,142 \\
(-1,91)^{*}\end{array}$ & $\begin{array}{c}-0,4070 \\
(-7,18)^{* * *}\end{array}$ \\
\hline Teste de Wald & $2013,78^{* * *}$ & $864,95 * * *$ & $1067,34 * * *$ \\
\hline
\end{tabular}

Fonte: Resultados da pesquisa, obtidos a partir de IBGE (2004a)

Nota: Os testes Z estão entre parênteses abaixo dos valores dos coeficientes. ${ }^{* * *}$ Denota significância ao nível de $1 \%$. ${ }^{* *}$ Denota significância ao nível de $5 \%$. ${ }^{*}$ Denota significância ao nível de $10 \%$.

Nos domicílios onde o chefe da família é homem há maior probabilidade de se consumir carnes do que em domicílios onde o chefe é mulher, porém no caso da carne suína essa variável não se mostrou significativa ao nível de $10 \%$. Já a idade da mulher, chefe de família ou cônjuge, apresentou um efeito significativo apenas para o consumo 
de carne bovina e suína. Os resultados mostram que os domicílios com donas de casa mais velhas apresentaram uma maior probabilidade de consumir carne bovina e uma menor probabilidade de consumir carne suína em relação às famílias com donas de casa mais jovens. A variável raça praticamente não se mostrou significativa na determinação da probabilidade de consumo de nenhum dos tipos de carne em análise.

A escolaridade da mulher chefe de família ou cônjuge afeta negativamente a probabilidade de consumo da carne de frango. Ou seja, um aumento de um ano na escolaridade da mulher reduz a probabilidade de consumo de frango em $0,3 \%$. Nos casos da carne bovina e suína o sinal negativo também indica uma relação inversa entre a escolaridade da mulher e a probabilidade de consumo, no entanto os coeficientes não foram significativos ao nível de $10 \%$.

As variáveis região e urbanização também apresentaram um efeito bastante significativo na determinação da probabilidade de consumo das carnes. Os domicílios situados na área rural são mais propensos ao consumo de carne suína, porém menos propensos ao consumo de carne bovina e de frango do que os situados no meio urbano.

No que se refere à localização regional, os domicílios situados na região Sudeste são menos propensos ao consumo domiciliar de carne bovina do que os situados nas outras regiões do país. No caso do consumo da carne suína, as famílias que moram na região Sudeste são mais propensas ao consumo do que as que vivem nas regiões Norte, Nordeste e Centro-Oeste, porém menos propensas do que as da região Sul. No caso da carne de frango, apenas os domicílios situados na região Centro-Oeste são menos propensos ao consumo, em todas as outras regiões a probabilidade de consumo de carne de frango é maior do que no Sudeste.

\subsubsection{Equações de dispêndio - efeitos marginais condicionais e não-condicionais}

As Tabelas 6 e 7 apresentam os resultados para as equações de dispêndio com os produtos: carne bovina, carne suína e frango. Na Tabela 6 constam os valores do efeito marginal condicional, que são efeitos obtidos considerando apenas os domicílios que consumiram cada uma 
das carnes. A Tabela 7 apresenta os resultados do efeito marginal nãocondicional, que são efeitos obtidos para toda a população e não somente para os consumidores do produto, como é o caso do efeito condicional. Para maiores detalhes sobre os efeitos marginais condicional e não-condicional, ver Hoffmann e Kassouf (2005).

Verifica-se que a renda domiciliar apresentou uma relação direta com o dispêndio. Os resultados mostram que um aumento na renda eleva o dispêndio com todos os produtos. No caso do efeito condicional, um aumento de $10 \%$ na renda domiciliar eleva o dispêndio com carne bovina em $2,1 \%$, com a carne suína em 2,0\% e com frango em 1,2\%. O maior efeito de um aumento na renda domiciliar foi sobre o dispêndio com a carne bovina e o menor foi sobre o dispêndio com frango.

Considerando o efeito não-condicional, ou os potenciais consumidores, um aumento de $10 \%$ na renda domiciliar eleva o gasto com carne bovina em 2,8\%, com carne suína em 3,7\% e com carne de frango em $1,9 \%$. Neste caso, o maior efeito de uma elevação na renda foi sobre o dispêndio com a carne suína, diferentemente do que ocorreu no caso do efeito condicional onde o maior efeito de uma elevação da renda foi sobre o dispêndio com a carne bovina.

Nos dois casos (efeito marginal condicional e não-condicional) o coeficiente da variável renda se mostrou altamente significativo na determinação do dispêndio com todos os tipos de carne analisados, apresentando apenas uma pequena variação na magnitude do efeito marginal. Para todos os tipos de carne o valor do efeito marginal não-condicional é maior do que o do efeito condicional. 
Tabela 6 - Efeito marginal condicional para o dispêndio com os produtos: carne bovina, carne suína e carne de frango

\begin{tabular}{lcccc}
\hline \multirow{2}{*}{ Variáveis (1) } & \multicolumn{3}{c}{ Equações de Dispêndio } \\
\cline { 2 - 4 } & Carne bovina & Carne suína & Carne de frango \\
\hline Renda domiciliar (log) & $0,214^{* * *}$ & $0,199^{* * *}$ & $0,117^{* * *}$ \\
Anos de escolaridade & $0,00752^{* * *}$ & $-0,0189^{* * *}$ & $0,00148^{* * *}$ \\
Área urbana & $-0,146^{* * *}$ & $-0,357^{* * *}$ & $-0,1079^{* * *}$ \\
Composição familiar & & & \\
Até 6 anos & 0,01014 & $-0,0243^{*}$ & 0,00957 \\
Entre 7 e 12 anos & 0,0152 & $-0,0336^{* * *}$ & $0,0248^{*}$ \\
Entre 13 e 18 anos & 0,0279 & $-0,02013^{* *}$ & $0,0432^{* * *}$ \\
Entre 19 e 25 anos & 0,0351 & $-0,0311^{* *}$ & $0,0355^{* *}$ \\
Entre 26 e 40 anos & $0,0668^{* *}$ & $0,0467^{* *}$ & $0,0485^{*}$ \\
Entre 41 e 60 anos & $0,0853^{* * *}$ & $0,0834^{* * *}$ & $0,07033^{* * *}$ \\
Mais de 60 anos & $0,116^{* * *}$ & $0,0881^{* * *}$ & $0,0917^{* * *}$ \\
\hline
\end{tabular}

Fonte: Resultados da pesquisa, obtidos a partir de IBGE (2004a)

Nota: ${ }^{* *}$ Denota significância ao nível de $1 \%$. * Denota significância ao nível de $5 \%$.

* Denota significância ao nível de $10 \%$.

(1) Como a variável dependente é o logaritmo do dispêndio, os valores do efeito marginal de todas as variáveis, excluindo a renda domiciliar que está em logaritmo, foram transformadas, utilizando-se a fórmula $[\exp (c)-1]$. Para maiores detalhes ver Hoffmann e Kassouf (2005).

O coeficiente da variável, anos de escolaridade da mulher também se mostrou altamente significativo para todas as carnes. No caso da carne bovina e de frango um aumento de um ano na escolaridade da mulher eleva o dispêndio domiciliar com esses produtos em 0,7\% e $0,1 \%$, respectivamente. Para a carne suína, o mesmo aumento reduz o dispêndio domiciliar com o produto em $1,9 \%$, isso para o caso do efeito marginal condicional. Ou seja, o aumento no nível de escolaridade da mulher que é chefe de família ou cônjuge eleva o dispêndio familiar com a carne bovina e de frango, mas numa proporção bastante baixa e reduz o dispêndio com a carne suína.

No caso do efeito marginal não-condicional o coeficiente da variável escolaridade da mulher teve um efeito positivo apenas para a carne bovina, mostrando que o aumento em um ano no estudo da mulher eleva o gasto com esse produto em $0,06 \%$, ou seja, numa proporção bastante 
baixa. O dispêndio domiciliar com a carne suína e de frango apresentou uma relação inversa com essa variável, mostrando que um aumento em um ano na escolaridade da mulher reduz o dispêndio domiciliar com a carne suína em $2,4 \%$ e com frango em $0,7 \%$. Ou seja, um aumento de um ano no estudo da mulher chefe da família ou cônjuge reduziu o dispêndio com a carne suína em 1,9\% para os reais consumidores e em $2,4 \%$ considerando os consumidores potenciais. No caso da carne bovina, o dispêndio da população consumidora aumentou em 0,7\% e da população potencial em 0,06\% .

Tabela 7 - Efeito marginal não-condicional para o dispêndio com os produtos: carne bovina, carne suína e carne de frango

\begin{tabular}{lcccc}
\hline \multirow{2}{*}{ Variáveis (1) } & \multicolumn{3}{c}{ Equações de Dispêndio } \\
\cline { 2 - 4 } & Carne bovina & Carne suína & Carne de frango \\
\hline Renda domiciliar (log) & $0,278^{* * *}$ & $0,370^{* * *}$ & $0,191^{* * *}$ \\
Anos de escolaridade & $0,000624^{* * *}$ & $-0,0236^{* * *}$ & $-0,00711^{* * *}$ \\
Área urbana & $-0,00892^{* * *}$ & $-0,0581^{* * *}$ & $-0,0655^{* * *}$ \\
Composição familiar & & & \\
Até 6 anos & $-0,00777$ & $-0,00178^{*}$ & 0,0275 \\
Entre 7 e 12 anos & 0,0214 & $0,0361^{* *}$ & $0,0658^{*}$ \\
Entre 13 e 18 anos & 0,0614 & $0,08034^{* *}$ & $0,133^{* * *}$ \\
Entre 19 e 25 anos & 0,0826 & $0,0277^{* *}$ & $0,111^{* *}$ \\
Entre 26 e 40 anos & $0,161^{* *}$ & $0,150^{* *}$ & $0,167^{*}$ \\
Entre 41 e 60 anos & $0,174^{* * *}$ & $0,2072^{* * *}$ & $0,190^{* * *}$ \\
Mais de 60 anos & $0,223^{* * *}$ & $0,132^{* * *}$ & $0,223^{* * *}$ \\
\hline
\end{tabular}

Fonte: Resultados da pesquisa, obtidos a partir de IBGE (2004a)

Nota: ${ }^{* *}$ Denota significância ao nível de $1 \%$. ${ }^{* *}$ Denota significância ao nível de $5 \%$. * Denota significância ao nível de $10 \%$.

(1) Como a variável dependente é o logaritmo do dispêndio, os valores do efeito marginal de todas as variáveis, excluindo a renda domiciliar que está em logaritmo, foram transformadas, utilizando-se a fórmula $[\exp (c)-1]$. Para maiores detalhes ver Hoffmann e Kassouf (2005).

No caso do frango, a escolaridade da mulher possui uma relação direta com o dispêndio domiciliar com o produto quando se considera o efeito condicional e quando se consideram os potenciais consumidores a relação é inversa, como pode ser observado nas Tabelas 6 e 7. Destaque-se que o resultado do efeito não-condicional está de acordo com 
o efeito negativo da escolaridade da mulher sobre a probabilidade de consumo de frango destacado na Tabela 5. Ou seja, existe uma grande discussão teórica a respeito dos efeitos marginais condicional e nãocondicional e os resultados aqui encontrados confirmam a importância da análise do efeito marginal não-condicional.

A urbanização também mostrou ter um efeito bastante significativo no dispêndio com as carnes quando se considera os reais consumidores ou o efeito marginal condicional. Domicílios da área urbana gastam 14,6\% menos com carne bovina em relação aos da área rural. No caso da carne suína o gasto domiciliar urbano é 35,7\% inferior ao rural e no caso do frango é 10,8\% inferior. O frango é o produto que apresentou a menor redução no dispêndio domiciliar urbano em relação ao rural e a carne suína a maior, o que mostra que o consumo de carne suína é bem mais significativo no meio rural.

Considerando os potenciais consumidores ou o efeito não-condicional, domicílios da área urbana gastaram 0,9\% menos com a carne bovina do que os da área rural. Para a carne suína a redução foi bem superior, $5,8 \%$. No caso do frango a redução no dispêndio urbano em relação ao rural foi de 6,6\%.

Destaque-se que os valores do efeito marginal são bem mais baixos quando se consideram os potenciais consumidores e não apenas os domicílios que realmente adquiriram os produtos. O que comprova a importância de se analisar os dois efeitos, principalmente porque, mesmo que a família não tenha adquirido o produto no período da pesquisa, a mesma não deixa de ser consumidora potencial e pode vir a consumi-lo a qualquer momento.

Considerando tanto o efeito marginal condicional quanto o nãocondicional, o coeficiente da variável composição familiar, no caso da carne bovina, apresentou uma relação direta com o dispêndio, o que significa que um aumento no tamanho da família eleva o dispêndio domiciliar com essa carne, porém essa variável só se mostrou significativa para as faixas de idade acima de 25 anos. No caso da carne de frango, a composição familiar também apresentou uma relação direta com o dispêndio, como pode ser observado nas Tabelas 6 e 7 .

Para a carne suína, um aumento no número de pessoas com até 25 anos de idade na família reduziu o dispêndio domiciliar com esse 
produto, enquanto um aumento no número de pessoas com mais de 25 anos na família elevou o dispêndio. No caso do efeito não-condicional, um aumento no número de crianças de até 6 anos na família teve o efeito de reduzir o dispêndio com a carne suína. Para todas as outras faixas etárias, a composição familiar foi diretamente relacionada ao dispêndio, como pode ser observado na Tabela 7 .

\section{Conclusões}

Dados da POF 2002-2003 mostraram que a carne bovina ainda é a carne mais consumida pelas famílias brasileiras, com uma aquisição domiciliar per capita anual de 17,7kg. Em segundo lugar aparece a carne de frango, com uma aquisição per capita de $13,6 \mathrm{~kg}$ e em terceiro a carne suína com $4,6 \mathrm{~kg}$.

A análise econométrica mostrou que todas as variáveis - nível de renda, urbanização, escolaridade da mulher e composição familiar - foram altamente significativas, tanto na determinação da probabilidade de consumo quanto no dispêndio com as carnes analisadas. A renda domiciliar apresentou um efeito positivo, tanto na probabilidade de consumo quanto no dispêndio familiar com os três tipos de carne, ou seja, um aumento na renda eleva a probabilidade de consumo e o dispêndio domiciliar com a carne bovina, suína e de frango.

O processo de urbanização, que se intensificou de forma bastante significativa nas últimas décadas, apresentou um efeito negativo na probabilidade de consumo de carne suína e um efeito positivo na probabilidade de consumo de frango e de carne bovina. No que se refere ao dispêndio, a urbanização afetou negativamente o dispêndio domiciliar com todas as carnes analisadas.

O coeficiente da variável composição familiar mostrou que um aumento no tamanho da família eleva a probabilidade de consumo das carnes bovina, suína e de frango, sendo que apenas a magnitude do efeito difere um pouco de produto para produto.

A escolaridade da mulher chefe de família ou cônjuge mostrou-se altamente significativa e com uma importante influência na determinação dos padrões de dispêndio domiciliar com as carnes bovina, suína e de frango no Brasil. Em uma análise para os potenciais consumidores, a 
escolaridade da mulher foi inversamente relacionada com o dispêndio domiciliar com as carnes, suína e de frango e diretamente relacionada com o dispêndio com a carne bovina.

Por fim, observou-se uma maior probabilidade de consumo domiciliar de carne bovina e de frango nas regiões mais pobres do país, o que pode ser devido ao baixo preço. Esse resultado também pode estar relacionado a um maior consumo de alimentação fora do domicílio nas regiões Sul e Sudeste e, portanto, menor consumo de carne no domicílio.

Além disso, o menor consumo domiciliar de carne suína vis-à-vis ao consumo de carne bovina e de frango, deve-se, em grande parte, a dois fatores: a importância que a população brasileira ainda dá aos mitos e lendas relacionados a possíveis impactos negativos do consumo da carne suína sobre a saúde e a falta de cortes específicos de baixo valor agregado, acessíveis à população de baixa renda.

\section{Referências bibliográficas}

BECKER, G.S. A theory of the allocation of time. The Economic Journal, New York, v. 75, n. 299, p. 493-517, Sep. 1965.

BERTASSO, B.F. 0 consumo alimentar em regiões metropolitanas brasileiras análise da pesquisa de orçamentos familiares/IBGE 1995/96. 2000. 109 p. Dissertação (Mestrado em Economia Aplicada) - Escola Superior de Agricultura "Luiz de Queiroz", Universidade de São Paulo, Piracicaba, 2000.

DEATON, A.; MUELLBAUER, J. Economics and consumer behavior. New York: Cambridge University Press, 1986. 450 p.

GREENE, W. Econometric Analysis. $4^{\text {th }}$ edition. New Jersey: Prentice Hall, 2003.

HECKMAN, J.J. Sample selection bias as a specification error. Econometrica, Menasha, v. 47, n. 1, p. 153-161, Jan. 1979.

HOFFMANN, R. A diminuição do consumo de feijão no Brasil. Estudos Econômicas, São Paulo, v. 25, n. 2, p. 189-201, maio/ago. 1995.

HOFFMANN, R.; KASSOUF, A.L. Deriving conditional and unconditional marginal effects in log earnings equations estimated by Heckman's 
procedure. Applied Economics, Londres, v. 37, n. 11, p. 1303-1311, June 2005.

INSTITUTO BRASILEIRO DE GEOGRAFIA E ESTATÍSTICA - IBGE. Pesquisa de orçamentos familiares 2002-2003: microdados: Brasil e grandes regiões. Rio de Janeiro: IBGE, Coordenação de Índices de Preços, 2004a. 1 CD-ROM.

INSTITUTO BRASILEIRO DE GEOGRAFIA E ESTATÍSTICA - IBGE. Pesquisa de orçamentos familiares 2002-2003: primeiros resultados: Brasil e grandes regiões. Rio de Janeiro: IBGE, Coordenação de Índices de Preços, 2004b. 276 p.

LANCASTER, K.J. A new approach to consumer theory. Journal of Political Economy, Chicago, v. 74, n. 2, p. 132-157, Apr. 1966.

McCRACKEN, V.A.; BRANDT, J.A. Household consumption of foodaway-from-home: total expenditure and type of food facility. American Journal of Agricultural Economics, New York, v. 69, n. 2, p. 274-284, May 1987.

PARK, J.L.; CAPPS, O. Jr. Demand for prepared meals by U.S. households. American Journal of Agricultural Economics, New York, v. 79, n. 3, p. 814-824, Aug. 1997.

PROCHASKA, F.J.; SCHRIMPER, R.A. Opportunity cost of time and other socioeconomic effects on away-from-home food consumption. American Journal of Agricultural Economics, New York, v. 55, n. 4, p. 595-603, Nov. 1973.

REDMAN, B.J. The impact of women's time allocation of expenditure for meals away-from-home and prepared foods. American Journal of Agricultural Economics, New York, v. 62, n. 2, p. 234-237, May 1980.

RUEL, M.T.; HADDAD, L.; GARRETT, J.L. Some urban facts of live: implications for research and policy. Washington, D.C.: International Food Policy Research Institute, Food Consumption and Nutrition Divison - FCND, Apr. 1999. 21 p. (Discussion Paper, 64).

SCHLINDWEIN, M. M. Influência do custo de oportunidade do tempo da mulher sobre o padrão de consumo alimentar das famílias brasi- 
leiras. 2006. 118 p. Tese (Doutorado em Economia Aplicada) - Escola Superior de Agricultura "Luiz de Queiroz", Universidade de São Paulo, Piracicaba, 2006.

SDRALI, D. Effects of sociodemographic and economic factors on food expenditure in a prefecture of Greece. Disponível em: < http:// www.lse.ac.uk/collections/hellenicObservatory/pdf/symposiumpapersonline/SDRALI.pdf > . Acesso em: 3 fev. 2005.

SENAUER, B. The effect of demographic shifts and changes in the income distribution on food-away-from-home expenditure. American Journal of Agricultural Economics, New York, v. 61, n. 5, p. 1046-1057, Dec. 1979.

SENAUER, B.; SAHN, D.; ALDERMAN, H. The effect of the value of time on food consumption patterns in developing countries: evidence from Sri Lanka. American Journal of Agricultural Economics, New York, v. 68, n. 4, p. 920-927, Nov. 1986.

SICHIERI, R.; CASTRO, J.F.G.; MOURA, A.S. Fatores associados ao padrão de consumo alimentar da população brasileira urbana. Caderno de Saúde Pública, Rio de Janeiro, v. 19, Supl. 1, p. 47-53, 2003. Disponível em: < http://www.scielo.br/scielo.php?pid = S0102-311X20030007 00006\&script $=$ sci_arttext\&tlng $=$ pt $>$. Acesso em: 26 jan. 2005 .

Recebido em março de 2006 e revisto em junho de 2006 